\title{
Ethical Issues in Genetic Testing for Inherited Cancer Predisposition Syndromes: the Potentially Conflicting Interests of Patients and Their Relatives
}

\author{
Joanna Kenny ${ }^{1,2} \cdot$ Stephanie Burcher ${ }^{1} \cdot$ Kelly Kohut $^{1} \cdot$ Nigel Eastman $^{3}$ \\ Published online: 17 March 2020 \\ (C) The Author(s) 2020
}

\begin{abstract}
Purpose of Review This review uses clinical cases to highlight some of the ethical dilemmas currently faced by oncologists, geneticists and others who request genetic testing for inherited cancer disorders.

Recent Findings Recent ethical guidance supports clinicians in testing patients when other family members decline similar testing, even when such testing will reveal those family members' genetic status. And increasingly there is acknowledgement that when a patient declines to share genetic results with family members, clinicians may have an ethical duty to breach patient confidentiality in order to inform at-risk relatives to whom they may owe a duty of care, so that they can choose to access genetic testing and potentially life-saving screening and treatment.

Summary Genetic testing for inherited cancer disorders raises multiple ethical issues, which cannot always be easily resolved by discussion with patients, or with their family members. Clinical ethics committees can provide valuable assistance in resolving the dilemmas presented in these cases.
\end{abstract}

Keywords Cancer $\cdot$ Predictive genetic testing $\cdot$ Confidentiality $\cdot$ Duty of care $\cdot$ Ethics

\section{Introduction}

Diagnostic genetic testing is often undertaken around the time that a patient has received a life-changing cancer diagnosis and is undergoing treatment. It may also be the first time that an inherited cancer predisposition has been suspected in the

JK is Secretary of the St George's Clinical Ethics Committee.

NE is Chairman of the St George's Clinical Ethics Committee.

We do not discuss whether there can or should be, in some cases, a legal duty to disclose genetic information to some relatives against the wishes of the patient.

This article is part of the Topical Collection on Cancer Genomics

Joanna Kenny

janna.kenny@nhs.net

1 St George's University Hospitals NHS Foundation Trust, London, UK

2 Department of Clinical Genetics, St George's Hospital, Blackshaw Road, Tooting, London SW17 OQT, UK

3 St George's, University of London, Cranmer Terrace, London SW17 ORE, UK family; and the possibility of such a disposition clearly has profound potential implications for other family members, which may include adults and children, and both near and more distant relatives. The greater availability of screening for early detection of cancer has increased the importance of relatives being made aware of inherited cancer predisposition syndrome diagnoses, so that they can access appropriate medical services. Hence, genetic testing of relatives for inherited cancer syndromes is a frequent topic of ethical discussion in both genetics departments and clinical ethics committees.

At present, it is generally considered to be the responsibility of the patient to disseminate their relevant genetic information appropriately to their relatives $[1 \bullet \bullet]$. Clinicians may, and usually do, help to facilitate this by providing patients with a letter or leaflet to pass to relevant family members. However, there is no formal procedure in place for ascertaining whether this has happened; or for determining what to do if it becomes clear that it has not. Also, several studies have found patients do not always inform family members of their risk, with barriers to disseminating this information including a desire to protect oneself and/or family from potentially distressing information, lack of contact or closeness with relatives and/or poor understanding of the risks posed and its relevance to others $[2,3,4 \bullet]$. 
Most families do understand the importance of sharing their genetic information with relatives, and outright refusal to inform relatives is rare. However, in our practice in the South West Thames Regional Genetics Service at St George's Hospital, London, we have encountered cases over a number of years where disclosure has been refused. Our policy then is to discuss the case in the departmental meeting in the first instance, and then to take the case to the hospital clinical ethics committee (CEC) if a consensus cannot be reached. We also take to the CEC cases where we are considering contravening the wishes of the patient. Finally, there is also available a national forum in the UK, called Genethics, available for discussing ethically challenging cases (genethicsforum.ning.com).

Here we discuss two of our recent ethically difficult cases, with a view to highlighting some of the major ethical issues that can arise concerning the diagnosis and disclosure of inherited cancer predisposition syndromes. Some details of the cases, including names, have been changed so as to protect patient confidentiality.

\section{Cases}

The Clinical Ethics Committee at St George's Hospital, London, is a multidisciplinary committee sponsored by the Trust and the University comprising doctors, nurses, allied health professionals, two health care students, and lay individuals who meet monthly, or urgently, to consider ethically complex cases arising in the hospital. Clinicians present cases to the committee, and members debate the ethical issues before potentially making a non-binding recommendation to the presenting clinicians about how to proceed. The minutes of the ethics committee meeting are usually placed into the patient's medical record, if so decided by the referring clinicians (albeit if they are not, then they are still legally discoverable), and have been used to support the actions of clinicians in the event of complaints or litigation, or can be used by litigants in actions against the hospital. Clinicians report often finding the ethics committee discussions and recommendations useful in informing decision-making and explaining these decisions to patients, families and other clinical teams.

\section{Case 1-BRCA2 Predictive Testing in an Identical Twin and Disclosure of Genetic Test Results Within a Family: the Right to Know, and the Right Not to Know}

\section{Background}

Clara was a patient known to Clinical Genetics who had not been seen for many years. She requested another appointment at the age of 38 years, attended with her husband and was seen by a genetic counsellor. Clara had been aware for some time that a $B R C A 2$ gene pathogenic variant was present in her family. Female carriers of such variants have up to $85 \%$ lifetime risk (up to age 80 ) of breast cancer compared with $12 \%$ population risk, and up to $\sim 30 \%$ risk of ovarian/fallopian tube cancer compared with $\sim 2 \%$ in the population. The variant was first identified in Clara's mother, who had breast cancer aged 39 years and died from ovarian cancer, which was diagnosed when she was aged 47 years. Clara's older sister had undergone predictive genetic testing, been found to carry the variant, and chose to pursue risk-reducing mastectomy and salpingo-oophorectomy. Clara had declined testing when she was seen in the genetics service previously, but was now starting to think about risk-reducing surgery, since she had completed her family and was approaching the age at which this is recommended. Clara said that her identical twin sister, Sarah, had also previously declined predictive testing some years ago and, unlike Clara, was still adamant that she did not wish to be tested. Both twins were receiving high-risk breast screening, with annual breast MRI (magnetic resonance imaging), which would not be indicated in the absence of carrying the familial BRCA2 pathogenic variant. Risks of unnecessary breast screening include increased anxiety and the potential for false positive results, leading to further investigation. There is no recommended surveillance for ovarian cancer, and risk-reducing bilateral salpingooophorectomy would not be recommended for an individual at 50\% risk. Following the genetic counselling session, Clara was keen to have predictive genetic testing, but explicitly stated that she would not inform Sarah about her result. The sisters had a close relationship, although they were living in different countries.

\section{Ethical Questions Raised by Case 1}

- How would Clara's result inform Sarah's risks?

- Does the choice by Sarah not to be tested preclude Clara from having the right to be tested?

- Do patients' relatives have a right to be made aware of genetic information from which they could benefit?

- Can the duty of confidentiality be breached in order to inform them, on the basis that they are owed a duty of care by the clinician?

- In what circumstances might healthcare professionals be able ethically to breach confidentiality?

\section{Principles of Medical Ethics as a Framework for Consideration of the Issues in Case $1^{1}$}

\section{Beneficence}

- Clara could potentially avoid physical harm to herself, if she was shown to carry the gene pathogenic variant, by

\footnotetext{
${ }^{1}$ A very commonly used 'model' for analysing ethically difficult dilemmas, offered in Beauchamp TL and Childress FL (2013) Principles of Biomedical Ethics, Seventh Edition, Oxford University Press, Oxford. There are, of course, other approaches to clinical ethical problem solving; for example, those in the 'utilitarian', rather than 'principled', tradition.
} 
putting in place measures to reduce her cancer risk (such as risk-reducing bilateral salpingo-oophorectomy)

- She could avoid the mental distress that would arise from continued uncertainty concerning her genetic status

\section{Non-maleficence}

- Non-disclosure of Clara's genetic test result to Sarah could result in her undergoing unnecessary breast screening (if the BRCA2 pathogenic variant were shown not to be present), or not pursuing riskreducing surgery (if the variant were shown to be present). Hence, non-disclosure of the test results on Clara could cause harm to Sarah.

\section{Justice and Autonomy}

- Patients have a right to access testing for themselves, so that Clara has a right to be tested.

- Relatives such as Sarah should not be 'forced' to know, or given without their consent, genetic test results relevant to them

Consultation with Clinical Ethics Committee Following discussion in departmental meetings, the case was discussed at a meeting of the hospital Clinical Ethics Committee ${ }^{2}$. There was unanimous agreement that Clara should be offered predictive $B R C A 2$ genetic testing. In that, it was concluded that the potential personal medical benefit to Clara outweighed the duty to avoid her sister inadvertently becoming aware of the result. Also, although the sisters had grown up believing they were identical twins, they had not undergone zygosity testing, and so there was a small chance that they were non-identical. Finally, once Clara had undergone genetic testing, it would still be recommended that Sarah undertake independent testing to confirm her own result, which could be pursued independent of Clara being tested, or independent of the results of such testing.

The outcome of the case was that Clara proceeded with genetic testing, whilst respecting Sarah's autonomy and choice not to pursue testing.

\section{Case 2-Lynch Syndrome Investigations and Non-disclosure of Results to Relatives}

\section{Background}

Joan (57) was diagnosed with endometrial cancer at 56 years and was referred to the clinical genetics service by her

\footnotetext{
$\overline{2}$ The Committee offers 'facilitation' of ethical consideration of cases, rather than either prescribing or proscribing particular ethical decisions.
}

oncologist in order to discuss her personal and family history of cancer.

Joan attended the appointment alone and was seen by a genetic counsellor. She had undergone a total hysterectomy and bilateral salpingo-oophorectomy, and was nearing the end of her radiotherapy treatment. During the genetic counselling appointment, she was informed that her personal and family history of cancer might be suggestive of a hereditary cancer predisposition condition called Lynch syndrome. It was noted that Joan's sister had been diagnosed with colorectal cancer at 48 years and her mother had been diagnosed with renal cancer (histology unknown) at 41 years.

Lynch syndrome is an inherited cancer predisposition syndrome associated with a pathogenic variant in $M L H 1, M S H 2$, MSH6 or PMS2. Cancer risks vary according to the gene, but risks for certain cancers are significantly higher than the general population risk. This can be as high as $75 \%$ lifetime risk of bowel cancer in males, with up to a 55\% lifetime risk of bowel cancer in females and $40 \%$ lifetime risk of endometrial cancer. The syndrome is also associated with gastric, ovarian and renal pelvis cancer, as well as several other cancers to a lesser extent. Screening recommendations include 2-yearly colonoscopies from 25 years of age, as regular bowel screening can significantly reduce the risk of developing bowel cancer. Risk-reducing hysterectomy and bilateral salpingooophorectomy are recommended for female Lynch carriers from the age of 40 years, although this is dependent upon which gene is involved in the family. Individuals with a pathogenic variant associated with Lynch syndrome have a 50\% chance of passing the variant on to a child.

Tumours caused by Lynch syndrome tend to show certain characteristics, and Lynch syndrome testing is often initially performed by looking for protein markers within the tumour, using immunohistochemistry of the mismatch repair proteins (MMR-IHC). These proteins are called MLH1, MSH2, MSH6 and PMS2. If one or more proteins is/are missing, it is possible that the cancer diagnosis is attributable to Lynch syndrome.

Joan consented to undergo genetic investigation of her stored endometrial cancer sample. The results demonstrated an abnormal staining pattern (loss of expression of the MSH2 and MSH6 proteins), suggestive of Lynch syndrome.

The genetic counsellor wrote to Joan with the results, plus information about the next steps, which included arranging germline testing for the MSH2 and MSH6 genes in order to determine whether the loss of protein expression was caused by a pathogenic variant in one of the genes, causing Lynch syndrome. When the genetic counsellor called Joan a few weeks later to follow up on the letter, Joan informed her that she had not opened her results letter and was not planning to do so in the near future. In subsequent phone calls, Joan declined any further genetic counselling appointments, and also declined a referral for colonoscopy. She also said that she would not share any of the 
information she had been given with her family. Her oncologist and surgeon also then raised concerns about a possible diagnosis of Lynch syndrome in Joan, as well as the risk to her relatives, but Joan again declined to engage in further discussion.

\section{Ethical Issues Raised by Case 2}

- Should we respect Joan's privacy and right to confidentiality?

- Do we have a duty to inform Joan's relatives of their potential genetic risk?

\section{Principles of Medical Ethics as a Framework for Consideration of Issues in Case 2}

\section{Beneficence}

- Non-disclosure may serve to sustain the clinician-patient relationship, which has value in itself

- Sustaining the relationship would offer some hope that Joan may later change her mind and agree to be tested, to her benefit and potentially to the benefit of her relatives

- Awareness now of the currently known genetic information would allow any relative of Joan's to decide to access tests, screening or treatment, to their benefit.

\section{Non-maleficence}

- Breaching confidentiality may cause mental distress to Joan, and so should be avoided.

\section{Autonomy}

- Any patient has the right to control dissemination of their medical, including genetic information

\section{Justice}

- All genetic information is inherently familial. Joan's refusal of further testing, and of disclosure of her current genetic information to her relatives, deprives those relatives of the opportunity to make choices about their own healthcare. That is, Joan's decision deprives her relatives of the opportunity of choice that she has taken for herself; so that they will remain unaware of their potential risks. Hence, Joan and her relatives are not being treated similarly and therefore 'fairly' by way of Joan's decisions.
Consultation with Clinical Ethics Committee Following discussion within departmental meetings, this case was discussed at a meeting of the hospital Clinical Ethics Committee. The CEC supported the genetics service speaking to other members of Joan's medical team in order to encourage her to undergo germline testing and to disclose the information to her relatives. It was further determined that, if she continued to refuse testing and disclosure, a letter should be sent to her sons inviting them to contact their local genetics service if they would like to discuss the known family history of cancer, that is falling short of disclosure of any genetic information concerning Joan.

At the time of writing, the case is still ongoing.

\section{Discussion}

Whilst quite different in their detail genetically and clinically, both of these cases address the fact that genetic information is, by definition, shared, at least in part, by multiple family members.

The right of patients to undergo predictive genetic testing, even when this may reveal information about other family members who may not wish to have testing, is an established one, albeit this has not always been the case [5]. However, the accepted ethical convention is for the geneticist or genetic counsellor to discuss the implications of this with the proband or patient, and in many cases, this proves to be accepted. Testing of the intervening relative (person in the family tree in between the relative who is known to carry the pathogenic gene variant and the person presenting) has advantages of avoiding inadvertent disclosure of carrier status by revealing that a relative is an obligate carrier; it refines the risk for the original patient and may avoid the need for testing if the intervening relative tests negative. However, this approach is not possible in all cases.

The ethical implications are particularly challenging when dealing with identical twins since, by definition, the testing of one twin reveals the status of the other. However, even if neither twin undergoes testing, if one develops the familial disease under consideration, the risks to the other are likely to be clarified in any event. Albeit there is always the possibility, especially in the case of commoner cancers such as breast cancer, that the diagnosis might be coincidental. A case of twin testing was reported in South Africa, where zygosity testing was suggested to clarify the probability of the twins being identical before a predictive test for Huntington disease [6]. However, the twin who did not wish to be tested declined zygosity testing and predictive testing went ahead for the other 
twin despite concerns being raised by the team looking after the twin who did not wish to be tested.

Ethical issues are often discussed using the four pillars mentioned above, that is 'autonomy', 'beneficence' and 'non-maleficence' and 'justice'. However, when considering the rights of more than one individual to be tested, or not, clearly these pillars may stand in direct opposition to one another.

The principle of autonomy would infer that Clara has the right to be tested, and that Sarah has the right not to be tested. The principle of beneficence suggests that testing Clara is the right course, but that not forcing, or risking disclosure to Sarah of Clara's test results is also right. Non-maleficence in Sarah's case would infer avoiding risking the trauma of learning an unwanted test result, whereas in Clara's case it would infer allowing her to control this aspect of her life and medical treatment. So that, no matter which course is chosen, it will inevitably prioritise the rights of one twin over those of the other.

Some of these conflicts of ethical principle can be avoided if the family member who would wish to decline testing remains unaware of the result. However, there are significant practical problems in maintaining this, particularly if family members are emotionally or geographically close. In Clara's case, even if Clara did not inform Sarah of her result, it is likely that Sarah might become aware of it, should Clara be found to have the pathogenic variant and choose to proceed along the route of prophylactic surgery.

The second case also raises issues of information sharing amongst families. In this case, however, the at-risk family members are unaware of the risk in play and cannot be consulted as to their opinions (without disclosure occurring). In addition, the causative mutation has not been identified in the proband, which may limit the ability to offer genetic testing to other family members in the event that they were to become aware of the risks. Furthermore, although unlikely in the context of the family history, it is also possible that the loss of MSH2 and MSH6 has occurred as an acquired (somatic) event rather than inherited, and that other family members are not at risk.

Discussions about information-sharing form an essential part of the clinical genetics consultation and, in general, family members are happy to inform family members of any emergent risk. Indeed, gaining information for the benefit of relatives is an important motivator for many people in seeking genetic testing, although the process of informing the family can then still be difficult [7, 8]. Despite this, there is evidence that relevant information about genetic risk may well not be passed on to family members, even when patients appear willing to share it. And, in some cases, the significance of the information may not be understood by family members even when that information appears to have been passed on by the proband [9].

The recent guidance from the Joint Committee for Genomic Medicine states that, where consent to inform relatives has been explicitly withheld, "it may be justified to break confidence where the avoidance of harm by the disclosure outweighs the patient's claim to confidentiality" [1]. This will involve weighing up the often competing ethical principles discussed above. Respecting the patient's right to confidentiality may be consistent with the principles of beneficence, non-maleficence and autonomy as far as the patient is concerned, whereas failure to breach may result in harm to the relative (contravening the principle of non-maleficence). It may also deny the relative the right to potentially life-saving medical treatment and the chance to make decisions about their own health, breaching the principles of both beneficence and autonomy.

The legal position in England and Wales is perhaps unclear, in terms of whether there can be not merely a potential right to disclose genetic information about a patient or proband to a 'third party' but whether there might sometimes be a duty to do so. Albeit there is a case ongoing in the English courts at present that may clarify the position in that jurisdiction [10 ${ }^{\bullet}$, which could, for example, be expressed in terms not of imposing 'a duty to disclose' but of a duty 'reasonably to carry out a balancing exercise' in regard to the interests of the patient or proband and of the third party (for example in the terms described above concerning the two cases presented). Previous cases in the USA, including that of Pate v Threlkel, have determined that it is sufficient for the doctor to tell the proband to inform the relative [11]. However, the case of Safer $v$ Estate of Pack suggests that this may not always be sufficient [12].

One concern that is frequently raised in discussion of such cases is whether breaching the patient's confidentiality will irreparably damage the clinician-patient relationship. Another is the practical difficulties involved in tracing relatives, especially where the proband is unwilling to assist, and in regard to determining what amounts to sufficient familial 'proximity' for a relative to be 'in the frame'. A third is whether knowledge that confidentiality may be breached so as to inform relatives of risks may act as a deterrent to people coming forward for genetic testing in the first instance. What is clear, perhaps, ethically is that the risks and benefits of any proposed breach should be weighed up in advance, discussion clearly documented, and the patient or proband informed of the proposed course of action, so as to be given the opportunity to assist in informing relatives before the breach is made if that is the decision come to [13]. And here referral to a clinical 
ethics committee may both assist the process per se and demonstrate that it has properly occurred.

\section{Conclusion}

Testing in cancer genetics is often complex in its clinical and ethical implications, and very frequently raises inevitable issues concerning other family members. So that explaining those issues to the proband, or patient, is a very important stage in the testing process. Clinicians not based in Clinical Genetics services who identify complex cases with regard to familial disclosure may wish to consider referral to a genetics clinician for further discussion, before testing is undertaken. In general, the refusal of a family member to access testing when a pathogenic variant has been identified in the family is not a sufficient reason to deny testing to other family members, even if such testing results in disclosure of carrier status for that individual. Refusal of a proband or patient to inform family members of a relevant genetic result may justify the clinician breaching patient confidentiality, but this should only be undertaken after attempts have been made to persuade the proband to disclose the information. Furthermore, the proband should be informed of the planned disclosure in advance. Whether law in England and Wales will develop towards, in some circumstances, there being a duty to disclose remains to be seen. The hospital clinical ethics committee, where available, may well be a valuable adjunct to decision-making, and its deliberations may assist in explaining and supporting such decisions.

\section{Compliance with Ethical Standards}

Conflict of Interest The authors declare that they have no conflicts of interest associated with this manuscript.

Human and Animal Rights and Informed Consent This article does not contain any studies with human or animal subjects performed by any of the authors.

Open Access This article is licensed under a Creative Commons Attribution 4.0 International License, which permits use, sharing, adaptation, distribution and reproduction in any medium or format, as long as you give appropriate credit to the original author(s) and the source, provide a link to the Creative Commons licence, and indicate if changes were made. The images or other third party material in this article are included in the article's Creative Commons licence, unless indicated otherwise in a credit line to the material. If material is not included in the article's Creative Commons licence and your intended use is not permitted by statutory regulation or exceeds the permitted use, you will need to obtain permission directly from the copyright holder. To view a copy of this licence, visit http://creativecommons.org/licenses/by/4.0/.

\section{References}

Papers of particular interest, published recently, have been highlighted as:

- Of importance

- Of major importance

1.• Medicine JCoGi 2019. Consent and confidentiality in genomic medicine report Royal College of Physicians UK: Royal College of Physicians UK; This is the most recent guidance aroiund consent and confidentiality for clinicians who deal with genetic and genomic testing.

2. Chivers Seymour K, Addington-Hall J, Lucassen AM, Foster CL. What facilitates or impedes family communication following genetic testing for cancer risk? A systematic review and meta-synthesis of priJoan qualitative research. J Genet Couns. 2010;19(4):330-42.

3. Koehly LM, Peterson SK, Watts BG, Kempf KK, Vernon SW, Gritz ER. A social network analysis of communication about hereditary nonpolyposis colorectal cancer genetic testing and family functioning. Cancer Epidemiol Biomark Prev. 2003;12(4):304-13.

4. Dheensa S, Lucassen A, Fenwick A. Limitations and pitfalls of using family letters to communicate genetic risk: a qualitative study with patients and healthcare professionals. J Genet Couns. 2018;27(3): 689-701 This study highlights the limited effectiveness of using family letters to communicate about a genetic variant, and sets the scene for future development of digital patient-facing tools.

5. Heimler A, Zanko A. Huntington disease: a case study describing the complexities and nuances of predictive testing of monozygotic twins. J Genet Couns. 1995;4(2):125-37.

6. Kromberg JG, Wessels TM. Ethical issues and Huntington's disease. S Afr Med J. 2013;103(12 Suppl 1):1023-6.

7. Hallowell N, Cooke S, Crawford G, Lucassen A, Parker M, Snowdon C. An investigation of patients' motivations for their participation in genetics-related research. J Med Ethics. 2010;36(1):37-45.

8. Leenen CH, Heijer M, van der Meer C, Kuipers EJ, van Leerdam ME, Wagner A. Genetic testing for Lynch syndrome: family communication and motivation. Familial Cancer. 2016;15(1):63-73.

9. Daly MB, Montgomery S, Bingler R, Ruth K. Communicating genetic test results within the family: is it lost in translation? A survey of relatives in the randomized six-step study. Familial Cancer. 2016;15(4):697-706.

10. Lucassen A, Gilbar R. Alerting relatives about heritable risks: the limits of confidentiality. BMJ. 2018;361:k1409 This article presents a current legal case balancing duty to warn with patient confidentiality, and suggests ways in which relatives can be warned without being given specific details about the index patient.

11. Florida, District Court of Appeal FD. Pate v. Threlkel. Wests South Report. 1994;640:183-6.

12. New Jersey, Superior Court AD. Safer v. Estate of Pack. Atl Report. 1996;677:1188-93.

13. Council GM 2017. Confidentiality: good practice in handling patient information. General Medical Council, United Kingdom of Great Britain and Northern Ireland.

Publisher's Note Springer Nature remains neutral with regard to jurisdictional claims in published maps and institutional affiliations. 